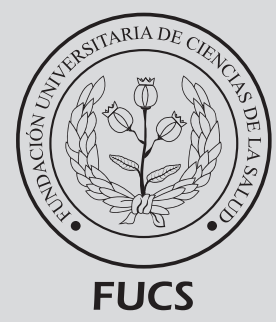

\title{
Uso de modelo predictivo para la dinámica de transmisión del Covid-19 en Colombia
}

\section{Use of predictive modeling for estimating Covid-19 transmission dynamics in Colombia}

\section{Uso de um modelo preditivo para a dinâmica de Transmissão Covid- 19 na Colômbia}

angeniero. Magister en Gestión de la Tecnología Educativa, Especialista en Administración de la Informática Educativa. Docente de matemáticas e Investigador, Secretaría de Educación de Soacha, Cundinamarca.

\section{R E S U M E N}

Introducción: los coronavirus son una amplia familia de virus que logran causar enfermedades tanto en animales como en humanos. En humanos, se sabe que varios coronavirus ocasionan infecciones respiratorias que consiguen ir desde el resfriado común hasta enfermedades más complicadas como el síndrome respiratorio de Oriente Medio (MERS) y el síndrome respiratorio agudo severo (SRAS). El coronavirus que se ha manifestado más recientemente causa la enfermedad por coronavirus COVID-19. Objetivo: presentar un pronóstico con el uso del modelo lineal de Brown de la dinámica de transmisión del COVID- 19 en Colombia. Materiales y métodos: para desarrollar la investigación se utilizó la base de datos de las personas infectadas con el COVID-19, la información de los datos corresponde al período 6 de marzo 2020 al 10 de mayo de 2020. Para su análisis de predicción se manejó el método de predicción modelo de BROWN, utilizando el paquete estadístico SPSS v.25. Resultados: se determinó por análisis de predicción que el número total de infectados por el COVID-19 en Colombia a 31 de agosto de 2020 estarán alrededor de 69848, de esta población 41110 corresponde a hombres y 28738 a mujeres Conclusiones: se evidenció una alta población de casos confirmados por coronavirus en Colombia a 31 de agosto de 2020; esto pone en alerta la red pública hospitalaria del país, además que obliga a las personas y comunidades a mantenerse en cuarentena por la emergencia sanitaria.

Palabras clave: coronavirus, transmisión de enfermedad infecciosa; modelos de transmisión de enfermedades, modelo computarizado.

Historia del artículo:

Fecha recibido: mayo 4 de 2020 Fecha aceptado: mayo 14 de 2020
Autor para correspondencia. Ing. Jorge Enrique Díaz-Pinzón jediazp@unal.edu.co
DOI

10.31260/RepertMedCir.01217372.1056 


\section{A BSTRACT}

Introduction: Coronaviruses is a broad family of viruses that manage to infect both animals and humans. Several coronaviruses are known to cause respiratory infections in humans, ranging from a common cold to more complicated conditions such as the Middle East Respiratory Syndrome (MERS) and the Severe Acute Respiratory Syndrome (SARS). The newly emerged coronavirus causes coronavirus disease 2019 (COVID-19). Objective: to predict the transmission dynamics of COVID-19 in Colombia using Brown's linear model. Materials and Methods: the database including people infected with Covid-19 was used to develop the research. This information corresponds to the period between March 62020 and May 10 2020. The Brown's model method was used for the predictive analysis in the SPSS v.25 statistical package. Results: our prediction analysis indicates that the number of people infected by COVID-19 in Colombia by August 312020 will be around 69848; of this population, 41110 would be men and 28738 women Conclusions: a high population of confirmed cases of coronavirus in Colombia is forecasted as of August 31 2020; this places the public hospital network of the country on alert and forces individuals and communities to remain in quarantine due to the health emergency.

Key words: coronavirus, infectious disease transmission; disease transmission models, computerized model

(C) 2020 Fundación Universitaria de Ciencias de la Salud - FUCS. This is an open access article under the CC BY-NC-ND license (http://creativecommons.org/licenses/by-nc-nd/4.0/).

\section{RESUMO}

Introdução: Os coronavírus são uma ampla família de vírus que conseguem causar doenças em animais e humanos. Em humanos, sabe-se que vários coronavírus causam infecções respiratórias que variam do resfriado comum a doenças mais complicadas, como a síndrome respiratória do Oriente Médio (MERS) e a síndrome respiratória aguda grave (SARS). O coronavírus manifestado mais recentemente causa a doença de coronavírus COVID-19. Objetivo: apresentar uma previsão com o uso do modelo linear de Brown da dinâmica de transmissão do COVID-19 na Colômbia. Metodologia: Para desenvolver a pesquisa, foi utilizado o banco de dados de pessoas infectadas com COVID-19, as informações dos dados correspondem ao período de 6 de março de 2020 a 20 de abril de 2020. Para sua análise de previsão, o método de previsão do modelo BROWN, usando o pacote estatístico SPSS v.25. Resultados: Foi determinado por análise de previsão que o número total de infectados com COVID-19 na Colômbia em 31 de julho seria de 33.219 casos confirmados, 17213 casos para homens e 16006 para mulheres. Conclusões: Uma alta população de casos confirmados por Coronavírus na Colômbia foi evidenciada em 31 de julho de 2020, o que coloca em alerta a rede de hospitais públicos do país, além de forçar a quarentena de pessoas e comunidades devido à emergência de saúde.

Key words: COVID-19, infecção, dinâmica de transmissão; modelos de transmissão de doenças, modelo computadorizado

(C) 2020 Fundación Universitaria de Ciencias de la Salud - FUCS. This is an open access article under the CC BY-NC-ND license (http://creativecommons.org/licenses/by-nc-nd/4.0/).

\section{INTRODUCCIÓN}

Los coronavirus son una amplia familia de virus que logran causar enfermedades tanto en animales como en humanos. En los humanos, se sabe que varios coronavirus ocasionan infecciones respiratorias que consiguen ir desde el resfriado común hasta enfermedades más complicadas como el síndrome respiratorio de Oriente Medio (MERS) y el síndrome respiratorio agudo severo (SRAS). El coronavirus que se ha manifestado más recientemente causa la enfermedad por coronavirus COVID-19. ${ }^{1}$ Según el Ministerio de Salud y Protección Social ${ }^{2}$, los coronavirus (CoV) son virus que brotan habitualmente en diferentes áreas del mundo y que causan infección respiratoria aguda (IRA), es decir gripa, que pueden llegar a ser leve, moderada o grave.
El nuevo coronavirus (COVID-19) ha sido clasificado por la Organización Mundial de la Salud como una emergencia en salud pública de importancia internacional (ESPII). Se han reconocido casos en todos los continentes y el 6 de marzo se confirmó el primero en Colombia. La infección se evidencia cuando una persona enferma tose o estornuda y expulsa partículas del virus que entran en contacto con otras personas.

En diciembre 2019 surgió una asociación de casos de neumonía en la ciudad de Wuhan (provincia de Hubei, China), con una muestra común a un mercado mayorista de mariscos, pescado y animales vivos. El 7 de enero 2020 las autoridades chinas establecieron como agente promotor 
del brote un nuevo virus de la familia corona viridae, que ulteriormente fue designado SARS-CoV-2. ${ }^{1}$ La secuencia genética fue compartida por las autoridades chinas el 12 de enero. La enfermedad ocasionada por este nuevo virus se ha designado por consenso internacional COVID-19. El Comité de Emergencias del Reglamento Sanitario Internacional (RSI, 2005) manifestó el brote como una emergencia de salud pública de importancia internacional (ESPII) en su reunión del 30 de enero 2020. Posteriormente, la OMS lo consideró como una pandemia global el 11 de marzo $2020 .^{3}$

“Estudiar la dinámica de un brote de enfermedades infecciosas recientemente surgido y en rápido crecimiento, como COVID-19, es importante pero desafiante debido a la limitada cantidad de datos disponibles". ${ }^{4}$

En Colombia el Instituto Nacional de Salud (INS) notifica diariamente al Ministerio de Salud y Protección Social las cifras de casos confirmados acumulados de COVID-19: total casos, en hospitalizaciones, ingresos en UCI, fallecidos y recuperados.

A pesar de las múltiples incertidumbres que, a nivel biológico, clínico y epidemiológico, siguen subsistiendo en relación con este nuevo virus, lo que ya parece claro es que cada país ha respondido o está respondiendo a la misma amenaza con diferentes medidas y/o con una temporización diferente. Este hecho hace que las curvas epidemiológicas de los países afectados se estén comportando de manera distinta, y que el costo social y económico de las respectivas respuestas pueda ser diferente. ${ }^{5}$

Según Montesinos ${ }^{6}$ el empleo de modelos matemáticos para enfermedades infecciosas ha aumentado en grado significativo en los postreros años debido a que suministran información ventajosa para tomar decisiones, y establecer medidas activas en el control o erradicación de una enfermedad infecciosa. Estos modelos son muy ventajosos porque sujetan propiedades esenciales de la dispersión de una enfermedad de una forma sintética. El objetivo de este trabajo de investigación es presentar unos modelos predictivos de la dinámica de transmisión del COVID-19 en Colombia, el método fue el modelo lineal de Brown, teniendo en cuenta el registro de la primera persona infectada el 6 de marzo 2020 hasta el 10 de mayo de 2020.

\section{TENDENCIA LINEAL DE BROWN}

Este modelo es apropiado para las series con una tendencia lineal y sin estacionalidad. Sus parámetros de suavizado son el nivel y la tendencia, que se admiten iguales. Por ello, el modelo de Brown es un caso específico del modelo de Holt. El modelo de suavizado exponencial de Brown es muy análogo a un modelo ARIMA con cero órdenes de auto regresión, dos órdenes de distinción y dos órdenes de media móvil, con el coeficiente para el segundo orden de media móvil igual al cuadrado de la mitad del coeficiente de primer orden. ${ }^{7}$
Este método radica en realizar dos suavizaciones exponenciales a partir de las cuales se alcanzará el valor estimado, o pronóstico que indagamos realizar, mediante un cálculo realizado con una expresión sencilla. La primera se emplea a los valores observados en la serie de tiempo y la segunda a la serie mitigada obtenida mediante la primera atenuación. Debido a que los valores calculados al realizar las dos primeras atenuaciones no son los datos considerados a obtener, es decir, que formarán las inferencias de los valores que se espera que tome la serie de tiempo en el futuro cercano, emplearemos una notación distinta a la de la expresión final con la cual se calculan los valores que componen en realidad el pronóstico., Este es el modelo más ventajoso para el pronóstico a corto plazo, se identifica porque busca mitigar los valores picos de la función por medio de un coeficiente denominado Alfa " $\alpha$ ". ${ }^{10}$

El objetivo de los métodos de serie de tiempo es manifestar un patrón en los datos históricos y luego extrapolarlo hacia el futuro; el pronóstico se fundamenta sólo en valores pasados de la variable que tratamos de predecir. ${ }^{11}$

A continuación, se presenta la formulación del método de Brown:

$$
\begin{aligned}
& \text { St } 1=(\alpha \times \mathrm{Xt})+[(1-\alpha) \times \text { St- } 1] \\
& \text { St } 2=(\alpha \times \text { St })+[(1-\alpha) \times \text { St- } 1] \\
& \text { at }=\text { St } 1+(\text { St } 1-\text { St } 2)=\text { St } 1-\text { St } 2 \\
& \text { bt }=\alpha /(1-\alpha)(\text { St } 1-\text { St } 2) \\
& \text { Ft }+\mathrm{m}=\text { at }+ \text { btm }
\end{aligned}
$$

Donde:

- Stl = Valor del suavizamiento exponencial simple al finalizar el periodo $t$

- St2 = Valor del suavizamiento exponencial doble al finalizar el periodo $\mathrm{t}$

- at $=$ Ajuste de la serie al finalizar el periodo $t$

- bt $=$ Ajuste de tendencia al finalizar el periodo $t$

- $\alpha=$ Constante de aislamiento

- $\mathrm{m}$ = Varia desde 1 hasta $\mathrm{m}$, y determina el número de pronósticos que se deseen

- $\mathrm{Ft}+\mathrm{m}=$ Pronostico en el periodo $\mathrm{t}+\mathrm{m}$

\section{MATERIALES Y MÉTODOS}

Según Hurtado y Toro (1998) citado por Díaz"12: “La investigación cuantitativa tiene una concepción lineal, es decir que haya claridad entre los elementos que conforman el problema, que tenga definición, limitarlos y saber con exactitud cómo se inicia el problema, también es importante saber qué tipo de incidencia existe entre sus elementos". Una de las particularidades de esta metodología es que nos admite asumir el rol de investigadores y docentes, de esta forma se podrá variar y tomar decisiones en los experimentos prescritos. ${ }^{13}$ El alcance de la investigación es de tipo exploratorio, de acuerdo $\operatorname{con}^{14}$ "se realiza cuando el objetivo consiste en examinar un tema poco estudiado". 
En lo relacionado con el diseño de la investigación es experimental, según señala ${ }^{15}$ son "estudios que se realizan sin la manipulación deliberada de las variables y en los que solo observan los fenómenos en su ambiente natural".

Para desarrollar la investigación se utilizó la base de datos de las personas con casos confirmados y la información por género con el COVID-19 de la página del Ministerio de Salud y Protección Social de Colombia (https:// coronaviruscolombia.gov.co/), la información de los datos corresponde al período 6 de marzo 2020 al 10 de mayo de 2020. Para su análisis de predicción se manejó el método de predicción modelo de Brown, utilizando el paquete estadístico SPSS v.25.
La variable $\mathrm{x}$ en el modelo es tiempo de inicio del primer contagiado en Colombia que fue el 6 de marzo 2020 hasta el 10 de mayo de 2020, estos datos al igual que la información por género, se ubicó en el paquete estadístico SPSS, la variable y corresponde al número de casos confirmados por el coronavirus en cada momento de tiempo establecido anteriormente, luego con esta información el sistema en su espacio de predicciones, se le da la indicación que proyecte hasta el 31 de agosto de 2020, para que nos dé la información de cuántas personas estarán contagiadas a esta fecha.

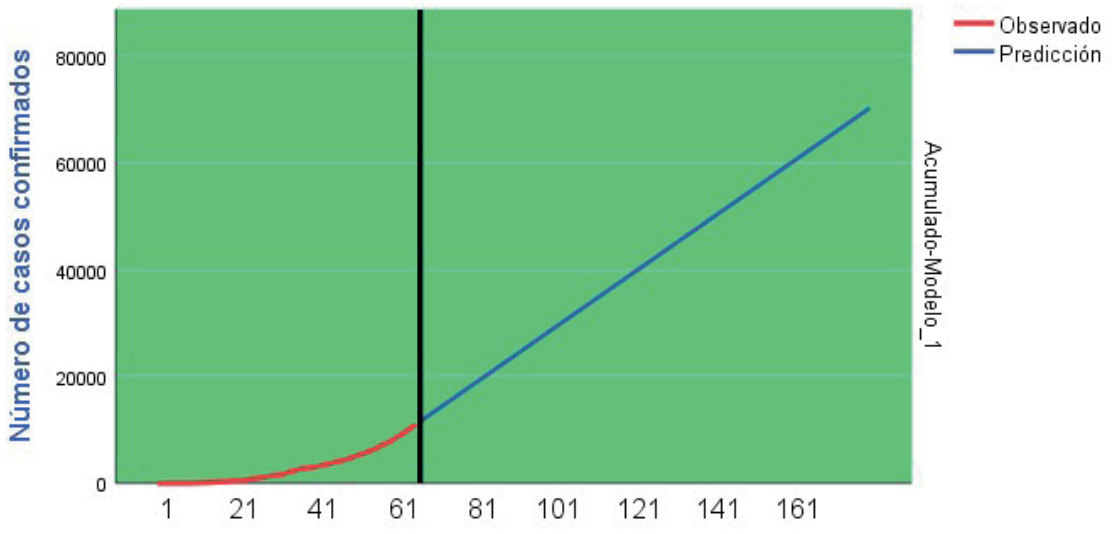

Días desde que se presentó el primer caso

Figura 1. Predicción Modelo de Brown de la dinámica de contagio del COVID-19 en Colombia por días (1-05-2020 hasta 31-08-2020). Elaborada en SPSS v. 25.

\section{RESULTA D OS}

En la Figura 1 podemos apreciar en la línea de color rojo el valor observado de la dinámica de contagio del COVID-19 en Colombia por días desde el 6 de marzo 2020 al 10 de mayo de 2020 y su respectiva predicción para los meses de junio, julio, y agosto de 2020 con la línea azul, con lo cual podemos realizar un pronóstico de las personas de casos confirmados acumulados con COVID-19 obtenido según el tiempo, como se observa en la siguiente ecuación: $\mathrm{Y}=520,3 \mathrm{x}+58921$. Los coeficientes 520,3 y 58921 definen la recta.

El coeficiente 520,3 es la pendiente de la recta; el cambio medio que se obtiene en el puntaje (Y) por cada unidad de cambio que se produce de tiempo en días (X) le corresponde un incremento de 58921 puntaje Y.

Esta tendencia lineal también es debida al ritmo de reproducción (R0), a comienzos de enero, el R0 para el coronavirus era de más de 2 . Escasamente dos meses después los cálculos proyectan un R0 de casi 6, más del doble de lo previsto al principio.

Concebir cómo funciona este número es significativo para comprender mejor cómo se va a dispersar la enfermedad en la población. ${ }^{16,17}$ Las estimaciones iniciales de la dinámica del brote en Wuhan, China, sugirieron un tiempo de duplicación del número de personas infectadas de 6 a 7 días y un número R0 de 2,2 a 2,7", registran los investigadores. ${ }^{18}$

En la tabla 1 se considera el pronóstico para el mes de junio 2020, los datos de las personas infectadas al finalizar el mes de junio de 2020 estarán alrededor de 37589, de esta población 21978 corresponde a los hombres y 15611 a mujeres. 
Tabla 1. Predicción contagiados de COVID-19. Método de BROWN para junio 2020

\begin{tabular}{|c|c|c|c|}
\hline Día & $\begin{array}{l}\text { Predicción de } \\
\text { Contagiados }\end{array}$ & Hombres & Mujeres \\
\hline 1-jun-20 & 22500 & 13029 & 9471 \\
\hline 2-jun-20 & 23021 & 13338 & 9683 \\
\hline 3-jun-20 & 23541 & 13646 & 9895 \\
\hline 4-jun-20 & 24061 & 13955 & 10106 \\
\hline 5-jun-20 & 24582 & 14264 & 10318 \\
\hline 6-jun-20 & 25102 & 14572 & 10530 \\
\hline 7-jun-20 & 25622 & 14881 & 10741 \\
\hline 8-jun-20 & 26142 & 15189 & 10953 \\
\hline 9-jun-20 & 26663 & 15498 & 11165 \\
\hline 10-jun-20 & 27183 & 15806 & 11377 \\
\hline 11-jun-20 & 27703 & 16115 & 11588 \\
\hline 12-jun-20 & 28224 & 16424 & 11800 \\
\hline 13-jun-20 & 28744 & 16732 & 12012 \\
\hline 14-jun-20 & 29264 & 17041 & 12223 \\
\hline 15 -jun -20 & 29785 & 17349 & 12436 \\
\hline 16-jun-20 & 30305 & 17658 & 12647 \\
\hline 17-jun-20 & 30825 & 17966 & 12859 \\
\hline 18-jun-20 & 31345 & 18275 & 13070 \\
\hline 19-jun-20 & 31866 & 18584 & 13282 \\
\hline 20-jun-20 & 32386 & 18892 & 13494 \\
\hline 21-jun-20 & 32906 & 19201 & 13705 \\
\hline 22-jun-20 & 33427 & 19509 & 13918 \\
\hline 23-jun-20 & 33947 & 19818 & 14129 \\
\hline 24-jun-20 & 34467 & 20127 & 14340 \\
\hline 25-jun-20 & 34988 & 20435 & 14553 \\
\hline 26-jun-20 & 35508 & 20744 & 14764 \\
\hline 27-jun-20 & 36028 & 21052 & 14976 \\
\hline 28-jun-20 & 36548 & 21361 & 15187 \\
\hline 29-jun-20 & 37069 & 21669 & 15400 \\
\hline 30-jun-20 & 37589 & 21978 & 15611 \\
\hline
\end{tabular}


Tabla 2. Predicción contagiados de COVID-19. Método de BROWN para julio 2020

\begin{tabular}{|c|c|c|c|}
\hline Día & $\begin{array}{l}\text { Predicción de } \\
\text { Contagiados }\end{array}$ & Hombres & Mujeres \\
\hline 1-jul-20 & 38109 & 22287 & 15822 \\
\hline 2-jul-20 & 38630 & 22595 & 16035 \\
\hline 3-jul-20 & 39150 & 22904 & 16246 \\
\hline 4- jul -20 & 39670 & 23212 & 16458 \\
\hline 5- jul -20 & 40191 & 23521 & 16670 \\
\hline 6- jul -20 & 40711 & 23830 & 16881 \\
\hline 7- jul -20 & 41231 & 24138 & 17093 \\
\hline 8- jul -20 & 41752 & 24447 & 17305 \\
\hline 9- jul -20 & 42272 & 24755 & 17517 \\
\hline $10-$ jul -20 & 42792 & 25064 & 17728 \\
\hline 11- jul -20 & 43312 & 25372 & 17940 \\
\hline 12- jul -20 & 43833 & 25681 & 18152 \\
\hline 13- jul -20 & 44353 & 25990 & 18363 \\
\hline 14- jul 20 & 44873 & 26298 & 18575 \\
\hline $15-$ jul -20 & 45394 & 26607 & 18787 \\
\hline $16-j u l-20$ & 45914 & 26915 & 18999 \\
\hline $17-$ jul -20 & 46434 & 27224 & 19210 \\
\hline $18-$ jul -20 & 46955 & 27533 & 19422 \\
\hline 19- jul -20 & 47475 & 27841 & 19634 \\
\hline 20- jul -20 & 47995 & 28150 & 19845 \\
\hline $21-$ jul -20 & 48515 & 28458 & 20057 \\
\hline 22- jul -20 & 49036 & 28767 & 20269 \\
\hline 23- jul -20 & 49556 & 29075 & 20481 \\
\hline 24- jul -20 & 50076 & 29384 & 20692 \\
\hline 25- jul -20 & 50597 & 29693 & 20904 \\
\hline 26- jul -20 & 51117 & 30001 & 21116 \\
\hline 27- jul -20 & 51637 & 30310 & 21327 \\
\hline 28- jul -20 & 52158 & 30618 & 21540 \\
\hline 29- jul -20 & 52678 & 30927 & 21751 \\
\hline 30- jul -20 & 53198 & 31235 & 21963 \\
\hline 31- jul -20 & 53718 & 31544 & 22174 \\
\hline
\end{tabular}


Tabla 3. Predicción contagiados de COVID-19. Método de BROWN para agosto 2020

\begin{tabular}{|c|c|c|c|}
\hline Día & $\begin{array}{l}\text { Predicción de } \\
\text { Contagiados }\end{array}$ & Hombres & Mujeres \\
\hline 1-ago-20 & 54239 & 31853 & 22386 \\
\hline 2-ago-20 & 54759 & 32161 & 22598 \\
\hline 3-ago-20 & 55279 & 32470 & 22809 \\
\hline 4-ago-20 & 55800 & 32778 & 23022 \\
\hline 5-ago-20 & 56320 & 33087 & 23233 \\
\hline 6-ago-20 & 56840 & 33396 & 23444 \\
\hline 7-ago-20 & 57361 & 33704 & 23657 \\
\hline 8-ago-20 & 57881 & 34013 & 23868 \\
\hline 9-ago-20 & 58401 & 34321 & 24080 \\
\hline 10-ago-20 & 58921 & 34630 & 24291 \\
\hline 11-ago-20 & 59442 & 34938 & 24504 \\
\hline 12-ago-20 & 59962 & 35247 & 24715 \\
\hline 13-may-20 & 60482 & 35556 & 24926 \\
\hline 14-ago-20 & 61003 & 35864 & 25139 \\
\hline 15-ago-20 & 61523 & 36173 & 25350 \\
\hline 16-ago-20 & 62043 & 36481 & 25562 \\
\hline 17-ago-20 & 62564 & 36790 & 25774 \\
\hline 18-ago-20 & 63084 & 37099 & 25985 \\
\hline 19-ago-20 & 63604 & 37407 & 26197 \\
\hline 20-ago-20 & 64125 & 37716 & 26409 \\
\hline 21-ago-20 & 64645 & 38024 & 26621 \\
\hline 22-ago-20 & 65165 & 38333 & 26832 \\
\hline 23-ago-20 & 65685 & 38641 & 27044 \\
\hline 24-ago-20 & 66206 & 38950 & 27256 \\
\hline 25-ago-20 & 66726 & 39259 & 27467 \\
\hline 26-ago-20 & 67246 & 39567 & 27679 \\
\hline 27-ago-20 & 67767 & 39876 & 27891 \\
\hline 28-ago-20 & 68287 & 40184 & 28103 \\
\hline 29-ago-20 & 68807 & 40493 & 28314 \\
\hline 30 -ago-20 & 69328 & 40802 & 28526 \\
\hline 31-ago-20 & 69848 & 41110 & 28738 \\
\hline
\end{tabular}


En la tabla 2 se estima el pronóstico para el mes de julio 2020, los datos de las personas infectadas al finalizar el mes de julio de 2020 estarán alrededor de 53718, de esta población 31544 corresponde a hombres y 22174 a mujeres.
En la tabla 3, se aprecia el pronóstico para agosto de 2020, los datos de las personas infectadas al finalizar el mes de agosto de 2020 estarán alrededor de 69848, de esta población 41110 corresponde a hombres y 28738 a mujeres.

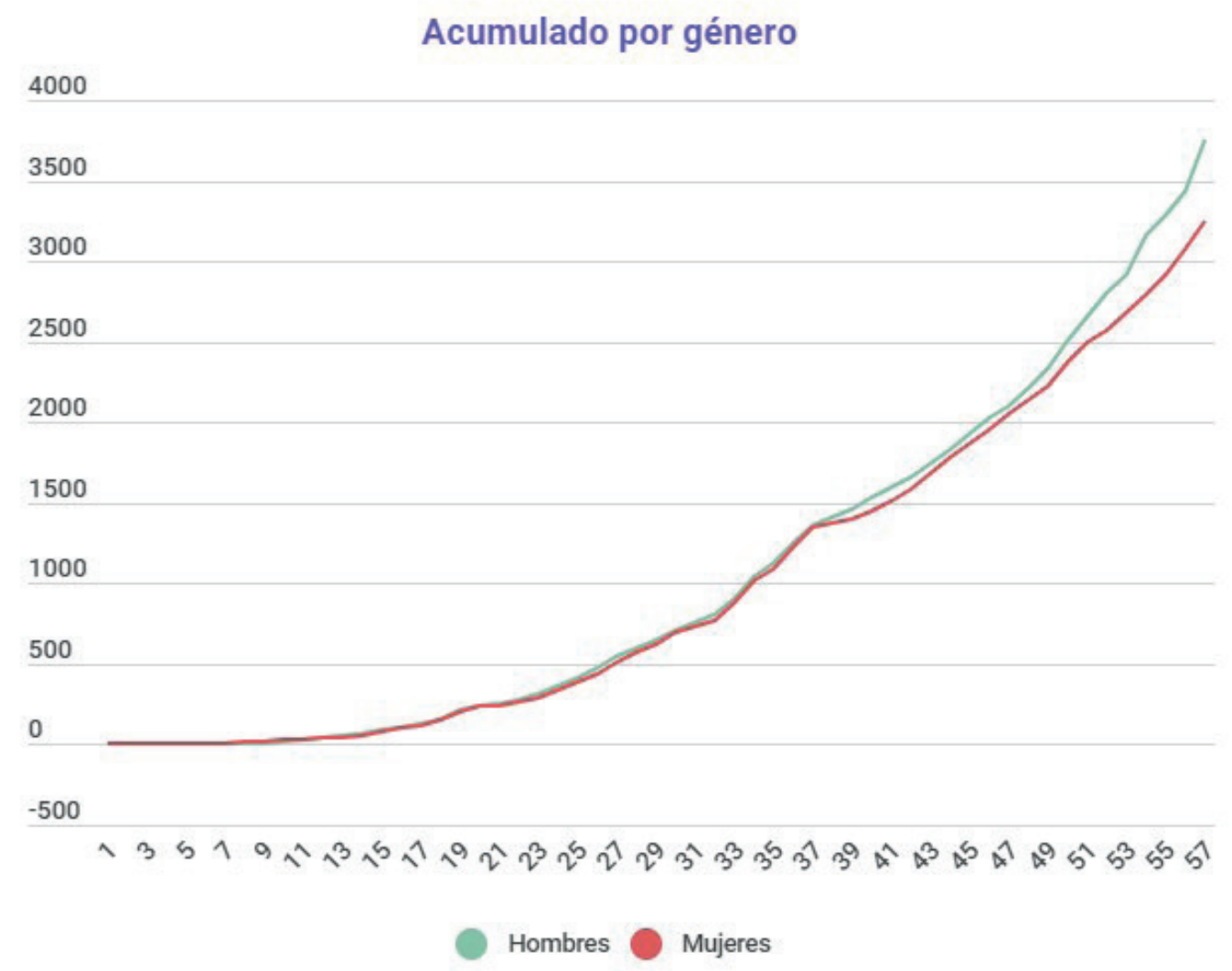

Figura 2. Acumulado por género del COVID-19 en Colombia por días (06-03-2020 hasta 01-05-2020). Elaborada en Infogram.

En la Figura 2..se describe el número acumulado de casos por género en Colombia, a partir del primer registro de recuperación 6 de marzo 2020 hasta 20 de mayo 2020. Al 1 de mayo 2020 se contaba con una población de contagiados de 7.006, de ellos 3.757 hombres y 3.249 mujeres.

En la figura 3 se describe el número acumulado de casos de personas recuperadas en Colombia, a partir del primer registro de recuperación 23 de marzo 2020 hasta 1 de mayo 2020. A 1 de mayo se recuperaron 1.551 personas de un total a la fecha de contagiados de 7.006, es decir que podemos determinar que $20,7 \%$ de la población afectada se ha recuperado.

En la figura 4 se observa el número de casos por grupo etario. En ella evidenciamos que el rango de edad más susceptible a contraer la enfermedad es 30 a 49 años, con 2.575 casos confirmados, seguidamente del rango entre 20 a 29 años, con 2.516 casos, y el rango que presenta cierta resistencia al contagio se encuentra en los rangos de 90 a 99 años con
62 casos, seguido del rango entre 80-89 años, con 252 casos y el rango entre 0-9 años con 465 casosaños con 42 casos, seguido del rango entre 80-89 años, con 149 casos y el rango entre 0-9 años con 241 casos.

\section{EL COEFICIENTE DE DETERMINACIÓN AJUSTADO $\left(\mathbf{R}^{2}\right)$}

El $\mathrm{R}^{2}$ coeficiente de determinación nos indica en qué medida los datos se ajustan al modelo seleccionado, tendencia lineal de Brown, en este caso el $\mathrm{R}^{2}=0,999$, y si se convierto a porcentaje se va obtener $99.5 \%$; esto significa que los datos se ajustan en $99,9 \%$ al modelo seleccionado. En la tabla 2 podemos observar la descripción del modelo utilizado Brown. 


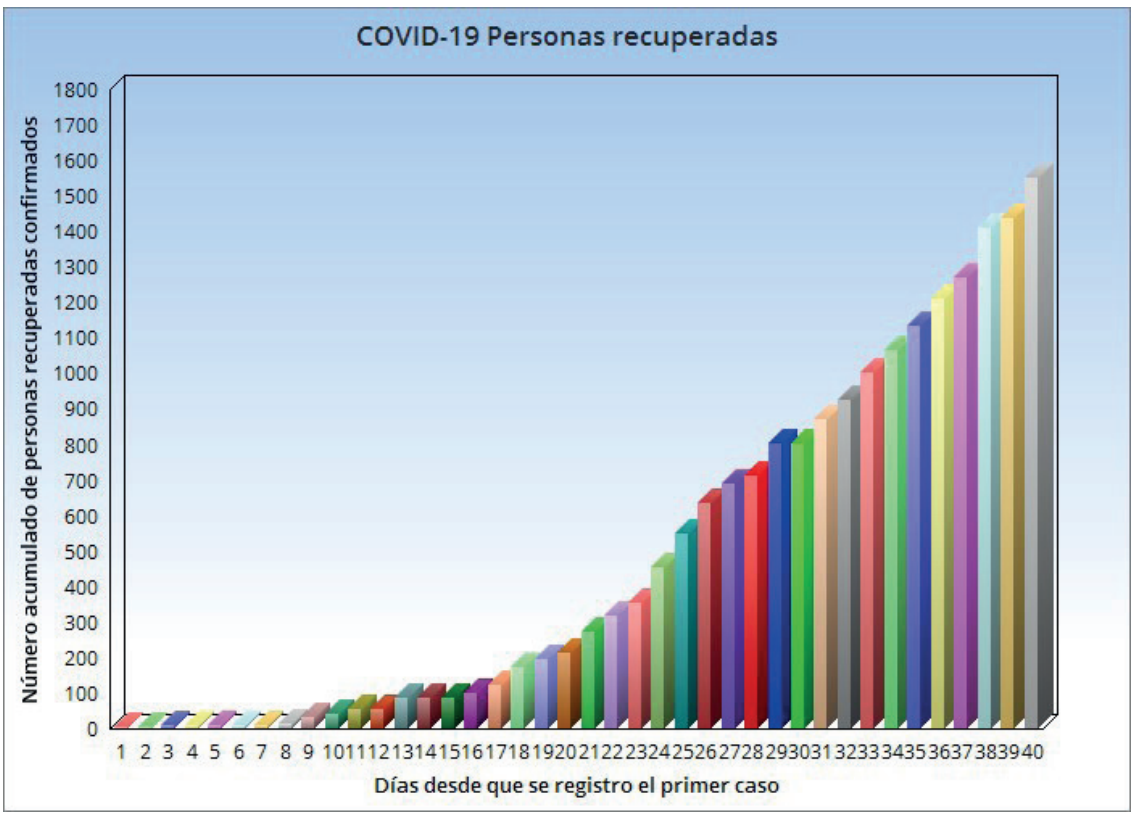

Figura 3. Número acumulado de personas recuperadas en Colombia (mayo 1 - 2020).

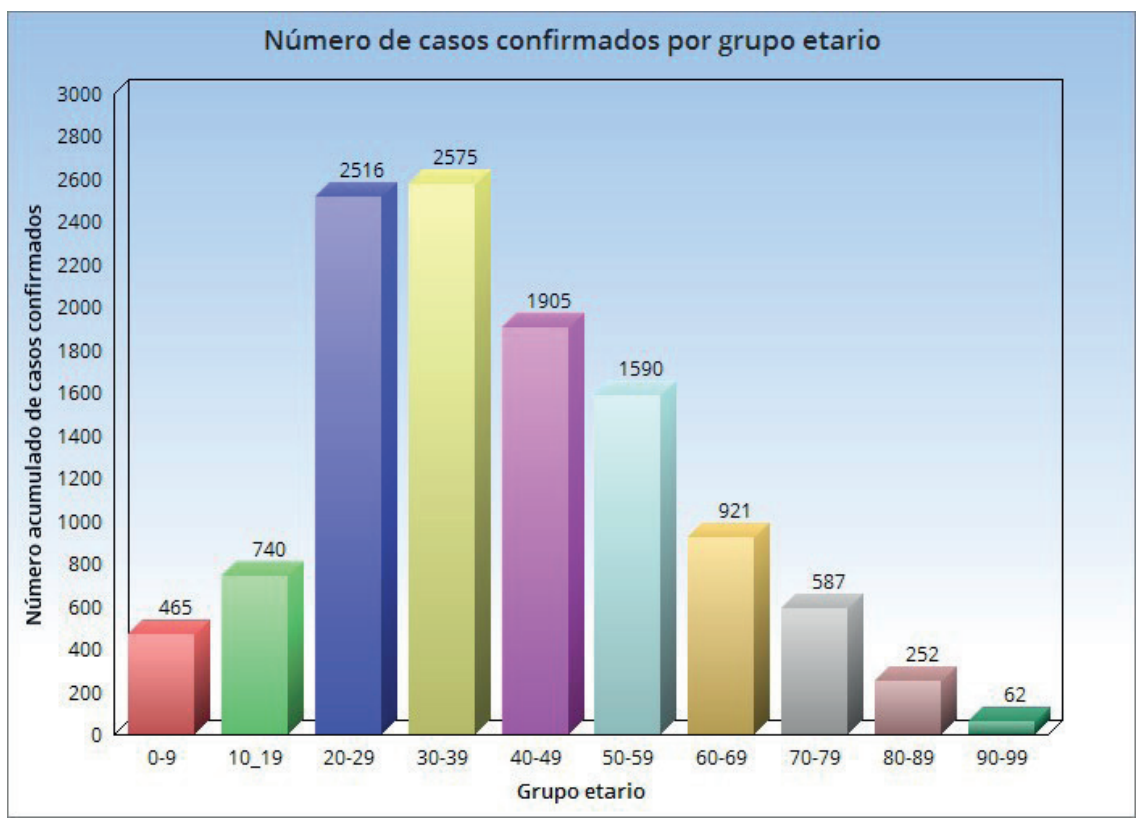

Figura 4. Número acumulado de casos en Colombia por grupo etario (mayo 10 de 2020).

\section{IS C US I ÓN}

De acuerdo con Díaz ${ }^{19}$, en su trabajo de investigación Precisión del pronóstico de la propagación del COVID-19 en Colombia, utilizando el método lineal de Brown, determinó que el error de pronóstico fue muy bajo, y correspondió al MAPE (error porcentual medio absoluto), con un 0,03\%, seguido del MAD (desviación media absoluta), con un valor de 0,95 , es decir que en ambos casos la predicción obtuvo un alto grado de confiabilidad.

El modelo de Brown nos ilustra un escenario posible de la enfermedad, lo cual a la luz de los resultados no es nada halagador para Colombia, por lo tanto, se hace necesario continuar con el asilamiento para que se genere una estabilización de la enfermedad. Esta predicción puede cambiar si todos los colombianos somos responsables en 
guardar la cuarentena. Este modelo analizado no tiene en cuenta el crecimiento hasta alcanzar un "pico" y es fundamental para el sistema sanitario saber cuándo se va a llegar, por lo tanto, es necesario realizar un monitoreo permanente para esclarecer el futuro de la enfermedad.

El autor recomienda realizar otro tipo de análisis con otros modelos matemáticos por ejemplo el modelo SIR es uno de los modelos epidemiológicos más simples idóneos de cautivar muchas de las características típicas de los brotes epidémicos. El nombre del modelo procede de las iniciales $S$ (población susceptible), I (población infectada) y $\mathrm{R}$ (población recuperada). El modelo concierne las variaciones las tres poblaciones (susceptible, infectada y recuperada) a través de la tasa de infección y el período infeccioso promedio. $^{20,21}$

\section{CONCLUSIONES}

Se determinó el pronóstico de las personas de casos confirmados acumulados con COVID-19 obtenido según el tiempo, como se observa en la siguiente ecuación: $Y=520,3 x$ +58921. Los coeficientes 520,3 y 58921 definen la recta. El coeficiente 520,3 es la pendiente de la recta; el cambio medio que se obtiene en el puntaje (Y) por cada unidad de cambio que se produce de tiempo en días $(\mathrm{X})$ le corresponde un incremento de 58921 puntaje Y.

Según el modelo predictivo de Brown, utilizado en esta investigación arrojó como resultados que los datos de las personas infectadas al finalizar el mes de junio 2020, estarán alrededor de 37589, de esta población 21978 corresponde a los hombres y 15611 a mujeres, los datos de las personas infectadas al finalizar el mes de julio de 2020 estarán alrededor de 53718, de esta población 31544 corresponde a hombres y 22174 a mujeres y en los datos de las personas infectadas al finalizar el mes de agosto de 2020 estarán alrededor de 69848, de esta población 41110 corresponde a hombres y 28738 a mujeres. El coeficiente de determinación $\mathrm{R}^{2}=0,999$, al convertirlo a porcentaje se obtuvo $99.9 \%$, esto significa que los datos se ajustan en 99,9\% al modelo seleccionado. El uso de modelación matemática se ha desarrollado en grado representativo en las últimas décadas y son de gran impulso para ilustrar escenarios eficaces de prevención y control de enfermedades infectocontagiosas.

\section{RECOMENDACIONES}

El autor recomienda basado en la predicción realizada a 31 de agosto de 2020, aumentar la infraestructura en relación con el aumento de camas de las unidades de cuidados intensivos, al igual que al aumento de respiradores mecánicos, esto basado en las proyecciones matemáticas de cuál va a ser la demanda y de esta manera las instituciones de salud puedan llevar a cabo los procesos administrativos para que los sistemas sanitarios sean capaces de responder en forma adecuada.

\section{CONFLICTO DE INTERESES}

El autor declara ningún conflicto de intereses

\section{REFERENCIAS}

1. Organización Mundial de la Salud OMS. Preguntas y respuestas sobre la enfermedad por coronavirus (COVID-19) [Internet]. 2020. [citado 2020 mar 26]. Disponible en: https://www. who.int/es/emergencies/diseases/novel-coronavirus-2019/ advice-for-public/q-a-coronaviruses

2. Ministerio de Salud y Protección Social. Orientaciones para el tamizaje de viajeros procedentes de zonas con circulación del nuevo coronavirus (COVID-19) [Internet]. 2020 [citado 2020 mar 26]. Disponible en: https://www.minsalud.gov.co/sites/ rid/Lists/BibliotecaDigital/RIDE/VS/asif04-guia-tamizajepoblacional-puntos-entrada-coronavirus.pdf

3. El Instituto de Salud Carlos III (ISCIII). Informe sobre la situación de COVID-19 en España. 2020 [Internet]. 2020 [citado 2020 mar 26]. Disponible en: https://www.isciii.es/ QueHacemos/Servicios/VigilanciaSaludPublicaRENAVE/ EnfermedadesTransmisibles/Paginas/InformesCOVID-19. aspx

4. Steven S, Yen Ting L, Chonggang X, Ethan R-S, Nick H, Ruian K. High Contagiousness and Rapid Spread of Severe Acute Respiratory Syndrome Coronavirus 2. Emerg Infect Dis. 2020;26(7). doi: https://doi.org/10.3201/eid2607.200282

5. Chaccour, C. COVID-19: Cinco respuestas de salud pública diferentes ante la epidemia [Internet]. 2020 [citado 2020 mar 26]. Disponible en: https://www.isglobal.org/healthisglobal/-/ custom-blog-portlet/COVID-19-cinco-respuestas-de-saludpublica-diferentes-ante-la-epidemia/2877257/0

6. Montesinos-López OA, Hernández-Suárez CM. Modelos matemáticos para enfermedades infecciosas. Salud Pública de Méx. 2007;49(3):218-26.

7. IBM Knowledge Center. Modelos personalizados de suavizado exponencial [Internet]. 2010 [citado 2020 mar 26]. Disponible en:https://www.ibm.com/support/knowledgecenter/es/ SSLVMB_sub/statistics_mainhelp_ddita/spss/trends/idh_ idd_exp_smooth_crit.html

8. Modelos de pronóstico. Suavización Exponencial Doble Método de Brown Ajuste a la Tendencia [Internet]. 2020 [citado 2020 abr 04]. Disponible en: http://modelosdepronosticos.info/ metodo_de_suavizacion_exponencial_doble_metodo_de_ brown.html

9. Coutin Marie G. Pronósticos de mortalidad por enfermedades no transmisibles seleccionadas. Rev Cubana Hig Epidemiol. 2008;46(3):1-14

10. Ramos Almanza DC, Bacca AP. Importancia de la planeación 
de la demanda en una empresa del sector industrial. Bogotá: Universidad Militar Nueva Granada; 2014. p. 23.

11. Villareal, F. Introducción a los Modelos de Pronósticos [Internet]. 2016 [citado 2020 abr 7]. Disponible en: https://www. matematica.uns.edu.ar/uma2016/material/Introduccion_a_ los_Modelos_de_Pronosticos.pdf

12. Díaz-Pinzón, J.E. Simulador applet descartes: como didáctica de enseñanza de la función cuadrática. IRJ. 2017;2(8):69-78. doi: https://doi.org/10.33890/innova.v2.n8.2017.256

13. Díaz Pinzón JE. Aprendizaje de las matemáticas con el uso de simulación. Sophia. 2018;14(1):22-30. doi: https://doi. org/10.18634/sophiaj.14v.1i.519

14. Hernández R, Fernández C, Baptista M. Metodología de la Investigación. 5 ed. México: McGraw-Hill; 2010.

15. Potts, C. Modelo computarizado del coronavirus: "Los asintomáticos son el gran riesgo" [Internet]. 2020 [citado 2020 mar 26]. Disponible en: https://www.dw.com/es/modelocomputarizado-del-coronavirus-los-asintom \% C3\%Alticosson-el-gran-riesgo/a-52798332

16. Cruz-Campillo, S. El ritmo de reproducción (R0) de la COVID-19 es el doble de lo que se estimaba y cinco veces mayor que el de la gripe [Internet] 2020. [citado 2020 abr 21]. Disponible en: https:// www.xataka.com/medicina-y-salud/ritmo-reproduccion-r0cOVID-19-doble-que-se-estimaba-cinco-veces-mayor-quegripe
17. Ridenhour B, Kowalik JM, Shay DK. El número reproductivo básico (R0): consideraciones para su aplicación en la salud póblica. Am J Public Health. 2018;108(Suppl 6):S455-S65. doi: https://doi. org/10.2105/AJPH.2013.301704s

18. Negrete, B. Coronavirus: 5 contagios por positivo, el doble de la estimación inicial [Internet] 2020. [citado 2020 abr 21]. Disponible en: https://www.redaccionmedica.com/secciones/sanidadhoy/coronavirus-5-contagios-por-positivo-el-doble-de-laestimacion-inicial-2648

19. Díaz Pinzón, JE. Precisión del pronóstico de la propagación del COVID-19 en Colombia. Repert. Med. Cir. 2020;29(Supl.1):27-33. doi: https://doi.org/10.31260/RepertMedCir.01217372.1045

20. Galindo Uribarri S, Rodríguez Meza MA, Cervantes Cota JL. Las matemáticas de las epidemias: caso México 2009 y otros. Ciencia Ergo Sum. 2009;20(3):238-46.

21. Navarro-Robles E, Martínez-Matsushita L, López-Molina R, FritzHernández J, Flores-Aldana BA, Mendoza-Pérez JC. Modelo para estimación del comportamiento epidémico de la influenza A (HINl) en México. Rev Panam Salud Publica. 2012;31(4):269-74. 